\title{
Students and Teachers' Causal Attributions to Course Failure and Repetition in an ELT Undergraduate Program
}

\author{
Lisseth S. Rojas-Barreto $^{1} \&$ Marco T. Artunduaga-Cuellar ${ }^{1}$ \\ ${ }^{1}$ School of Education, Universidad Surcolombiana, Neiva, Colombia \\ Correspondence: Lisseth S. Rojas-Barreto, Carrera 7 No 55-59, torre B, apto 403. Conjunto Torres de Varegal, \\ Neiva, Colombia. Tel: 57-320-230-2773. E-mails: lisseth.rojas@usco.edu.co; marcot.artunduaga@usco.edu.co
}

Received: March 2, 2018 Accepted: April 8, 2018 Online Published: April 10, 2018

doi: 10.5539/elt.v11n5p39 URL: http://doi.org/10.5539/elt.v11n5p39

\begin{abstract}
This article is the product of a diagnostic research study conducted by two professors from the APRENAP research group at Universidad Surcolombiana from Neiva, Huila, Colombia. The study aimed at looking into the causes for the English courses repetition phenomenon which was evident among many students especially in the advanced semesters at the ELT undergraduate program in the university. The main purpose of this qualitative study that followed the Grounded Theory principles was to determine to which factors the academic community of the program- professors and students- attributed the constant failure and repetition of advanced English courses by some students. Findings gathered from the analysis of a questionnaire and a semi-structured interview evidenced that variables such as a lack of autonomous learning habits, economic, labor and family responsibilities, and few hours of class, among others, affect negatively students' foreign language learning.
\end{abstract}

Keywords: English course failure, course repetition, perceptions, causal attributions, grounded theory, academic performance.

\section{Introduction}

The Colombian National Ministry of Education issued in 2006 the "Basic Standards of Competencies in Foreign Languages: English" which establishes that in order to earn their degree, students from ELT undergraduate programs must have at least a $\mathrm{C} 1$ level of competence in English according to the Common European Framework. In order to ensure compliance with that national policy, in our undergraduate program students are required to take an external examination in which they need to certify level B1 when they are in their intermediate level (fourth semester) and $\mathrm{C} 1$ in their advanced level (eighth semester). The external examination is used with promotion purposes as well as a strategy to evaluate the level of communicative competence in English that students have attained during their studies. Nevertheless, it has been observed that when students are in the middle of their studies (fourth semester) they generally show the required level of communicative competence expected for their level (B1). In contrast, students in the last semester (eighth), show a very different situation as their level of communicative competence in English is below or much lower than the $\mathrm{C} 1$ expected.

A comparison of the results of last year external test evidenced that $50 \%$ of students in fourth semester were in level B1, while $22.2 \%$ of them were in level B2 which means that more than $72 \%$ of those students were in the required level of competence in English. In the case of English VIII students, only 3.1\% of them reached the C1 level required by the Ministry of Education. It was also found that $31.2 \%$ of these students were close to the required level as they were placed in B2 whereas $65.6 \%$ of them were below the level expected for students finishing an undergraduate program in ELT.

Another element that confirmed the existence of the research problem was the low level of communicative competence many of our advanced level students showed which was directly related to their low academic performance in the English seventh and eighth courses. The fact that the same advanced-level students showed high levels of course failure and repetition was a worrying situation to the faculty and that called for urgent actions in order to identify the causes behind that problem.

Therefore, having students in an ELT undergraduate program who fail and repeat English courses in the last two levels of their studies is certainly a problem. But perhaps, the most worrying factor is that course failure and repetition are due to very low levels of academic performance together with an insufficient level of communicative 
competence in English. This situation was evidenced in a public university in Colombia where our research study was conducted in order to establish the causes behind the constant English-course failure and repetition problem. In the study, students' and professors' perceptions about the problem were taken into account. We wanted to find out what -in their opinions- were the causes they attributed to the phenomenon. To conduct the study, the Grounded Theory approach was the selected method.

All the previous facts helped us to state the following research question and objectives

\subsection{Research Question}

What are the causal attributions of students and professors regarding the English course repetition phenomenon in some students from the advanced levels?

\subsection{Objectives}

\subsubsection{Main Objective}

Identify the causal attributions that students and professors of an ELT undergraduate program give to the phenomenon of course repetition associated with the low academic performance in some students.

\subsubsection{Specific Objectives}

Diagnose the causes of the high repetition rate in the English VII and VIII courses in an ELT undergraduate program.

Propose some alternatives to deal with the phenomenon of English courses repetition evidenced by some students from the advanced levels in an ELT undergraduate Program.

\section{Literature review}

\subsection{Academic Failure and Course Repetition}

Academic failure is a complex phenomenon which might be understood as the prolongation, repetition or abandonment of studies compared to what is formally established for each program (González, 2005; Roman, 2014). Academic failure depends on social, scholar or biophysical factors. Social factors refer to the influence exerted by the different groups the individual belongs to, such as a group of friends, family climate etc, all these "may cause the student to take an indifferent attitude towards school" (Roman, 2014). In terms of school factors, it has to do with how the teacher teaches and how the student learns and develops during the learning process. Finally, the biophysical factors are related to the physical and mental development of students, such as endocrine disorders, neurological disorders, shortcomings of intellectual development, intellectual apathy, slowness etc. (Roman, 2014) In the case of the tertiary system the situation might differ from primary and secondary educational system, since university is not compulsory for everyone, therefore, students have the possibility to choose between continuing studying and going to labor market.

The main indicator of insufficient academic performance, the poor achievement of the proposed goals, and the low development of the expected competences of a student is the repetition of a course, which is defined by González (2005), as the action of coursing reiteratively a teaching activity, either due to poor performance of the student or for reasons beyond the academic field. This same author points out that this phenomenon can occur due to various factors depending on the curricular system and can refer to all the different academic activities of a given period (year, semester or quarter), or even to each subject.

In the specific context of our ELT undergraduate program, there are very serious issues that affect those students who fall behind. The biggest one is indeed the delay to graduate and thus begin to work. Most of these students have already fulfilled the other degree-earning requirements such as approving all other subjects, their teaching practicum, and bachelor's degree option. Therefore, having to repeat their advanced English courses undoubtedly impacts their economy because they have to pay the full semester even if it is just to take a course. Luckily, the dropout rate derived from this course repetition phenomenon is null among our students.

In the case of academic failure in the tertiary level, some research associated with the analysis of the factors which lead to such academic failure has been conducted. Roman (2014) planned to identify the main causes of student failure in a school of Cybernetics, Statistics, and Economic Informatics from the Bucharest University of Economics, that represents a special situation inside a university. The results suggested that economic and financial causes are responsible for students' failure (in cases when the student is not academically supported by their family), followed by scholar causes and biophysical causes. In like manner, they found "difficulties from technical and analytical disciplines, followed by teacher's level of exigencies and students' instrumental difficulties” (Román, 2014). 
Authors such as Holmes and Matthews (1984) and Shepard (1989) also conducted studies about the effects of course repetition in students. The majority of these authors highlight the lack of concluding evidence to support that course repetition favors students. On the contrary, the data gathered seem to prove that the effects are rather counterproductive and negative for those students.

It is important to point out that the majority of the studies conducted about course repetition have focused on the first scholar years in primary and high school education. Research about the course repetition phenomenon in superior education is rather scarce, and this is a very good reason why our study offered a meaningful opportunity to explore the problematic situation.

\subsection{Perceptions, Beliefs, Causal Attributions}

From long ago, different authors have tried to define the term perceptions or beliefs, as the one provided by Richardson (1996) who grouped the terms beliefs and perceptions as a set of mental constructs which name, define and describe the structure and contents of mental states which control people's actions. For Richardson (1996) and some other authors such as Pajares (1992) and Cortez, Fuentes, Villablanca, and Guzmán (2013), the concept makes reference to a set of ideas, premises, assertions and understandings related to any topic which are considered true and supported psychologically. On the other hand, Mercer (2008) made allusion to the term self- beliefs which refer to "the beliefs about oneself which are thought to affect behavior and attitudes." (p. 182).

In the language teaching field authors such as Larenas and Campos (2015) and Gómez (2017) assert that students' perceptions and beliefs regarding language teaching and learning are determinant to their academic progress, facilitating or hindering it. In other words, beliefs are conjectures made by students, around the aspects that intervene in the learning of a foreign language. However, these beliefs or perceptions can have a negative connotation when they are the result of previous experiences that have negatively affected students (Larenas \& Campos, 2015; Breen, 2014). As a result, those beliefs can make the teaching of a foreign language especially difficult and may be among the causes of course failure and repetition.

The analysis of teachers and students' beliefs and perceptions has been of high interest in the educational context. In the specific field of foreign languages, there have been several authors such as Kalaja and Barcelos (2003); Hawkey (2006); Brown (2009); Barrios (2014) and Gómez (2017) that have asked participants- students and teachers- to reflect about the L2 teaching / learning process as it is shown it the following researches:

Kalaja and Barcelos (2003) marked the resurgence of research on beliefs and perceptions in the learning and teaching of a second language. These authors present the efforts of many scholars to try to understand beliefs about the acquisition of a second language and how to study them effectively. For these researchers, the perceptions of teachers and students about the teaching-learning of a second language are not only experimental but also dynamic, socially constructed, paradoxical, interchangeable and contextually situated. Therefore, for the improvement of the teaching-learning process of a foreign language, a firm understanding of the beliefs and perceptions of the students is necessary.

Brown (2009) establishes that the perceptions and interpretations of students about the effective teaching of a foreign language have a high influence in the achievement of their goals. However, in some cases the perceptions and expectations of the students about the ideal behavior of the teachers in the classroom does not correspond with the intention of the teachers, which for some students can result in disappointment. In the comparative analysis done by the author, he found that teachers apparently pay more attention to a communicative approach in which information exchanges take precedence over the practice of particular aspects of grammar. Students on the other hand preferred an emphasis on the teaching of grammatical aspects over communicative exchanges. It proves the need for future studies on the correspondence between students and teachers' expectations regarding the teaching of a foreign language.

In relation to future teachers' beliefs Barrios (2013) developed a study aimed at investigating the beliefs about language learning exhibited by 307 prospective primary English language teachers. The purpose of the study was to collect information which would help him to guide their training in English language teaching, and thus to contribute to the professional knowledge regarding prospective English teachers' beliefs. According to the researcher, some of the findings "indicate that the participants hold some erroneous beliefs that the teaching education programme should address and confront with conceptions coherent with the current state of the art in the field of language learning research and professional knowledge" (p. 73).

Likewise, Gómez (2017) carried out a research study that aimed to identify the beliefs of university students about learning English with the purpose of improving the curriculum of that language in their institution as well as helping teachers to have a "Greater understanding of the factors that hinder or facilitate the learning of a foreign 
language" (p. 205). Among the results, the evidence suggests that "students' beliefs play an important role in the learning process of a foreign language, especially if the development of communicative competence in a second language is wanted" (p. 216). Thus, when those perceptions are not favorable they can be an obstacle to the learning process. The researcher also discovered that the vast majority of his participants have an instrumental and integrative motivation to learn English, "since this will enable them to access better job opportunities, travel to other countries and be part of a community of speakers of that language" (p. 216). Among the beliefs that represent challenges for the students he includes factors as: linguistic, affective, age, difficulty in understanding oral messages and the adequate context to learn the language. Therefore, these variables become a limiting factor which affect their performance in the foreign language.

On the other hand, authors such as Weiner (1985); Fernández, Arnaiz, Mejía, and Barca (2015) use the term "attributions" or "causal attributions". The theory of attributions states that subjects try to discover and understand the causes that explain what happens to them and how these causes are directly related to their own motivation. "Causal attributions imply a set of beliefs and causes that are perceived as responsible for an event or a determined behavior" (Fernández et al., 2015).

In the educational context, Williams, Burden, and Al-Baharna (2001) conducted a study on the attributions that students make to their success and failure in relation to learning English. The results revealed that practice, support from family and teachers, exposure to language and a positive attitude were the reasons most frequently cited by students for their success. In contrast, inadequate methods, lack of support from family and teachers, poor understanding and a negative attitude were the cause of their failure.

Likewise, Williams M. , Burden, Poulet, and Maun (2004) in their work wanted to find out about the attributions of students regarding their level of success and failure, and to establish how those vary according to age, gender, perceived success and specific language studied. In this study, the researchers applied a simple questionnaire, in which the students made a personal evaluation and presented their attributions. The results were analyzed and categorized according to the age and gender of the students, together with their level of success and perceived failure.

An important common factor among the studies in this area is that attributions do not necessarily reflect the "true" reasons why an individual can succeed or fail in any task. Rather, attributions are the perceived explanations that the individual constructs about their good or bad performance in any area. Those reasons are considered by the specialists in the attributional theory as more powerful than the real reasons. Another potential of the attributional theory mentioned by Kalaja and Barcelos (2003) is the fact that it is socially constructivist by nature, where a shared discourse can be found among the students about why they feel or are not able to learn. Besides, that discourse would be specific to a particular group or context. For our particular case, the attributions of the students and professors of the last semesters of the program regarding the research problem would yield highly relevant information to answer our research questions.

The previous experiences corroborate the viability and relevance of our study. That is why we decided to take into account the perceptions of the students and teachers of the EFL Teacher Education Program and the causal attributions given by them, to diagnose the causes of the phenomenon of English courses failure and repetition in the last semesters. In that way, in the future we want to be able to implement an action plan in order to overcome the problematic situation.

\section{Method}

\subsection{Grounded Theory}

It is a research qualitative method proposed by Glaser and Strauss (1967) which emphasizes in the construction of theory. It is called theory because its objective is collecting and analyzing the findings with the purpose of generating some theory and grounded because such theory is generated and based on the empirical data. (Bisquerra, 2014). "The grounded theory method (GTM) comprises a systematic, inductive and comparative approach for conducting inquiry for the purpose of constructing theory" (Bryant \& Charmaz, 2012). In this method, data collection and analysis progress at the same time and each informs and coordinates the other. The empirical findings lead the researcher to develop possible theoretical explanations in an inductive way (Bryant \& Charmaz, 2012; Bisquerra, 2014). In like manner, it has a repetitive process of moving back and forth between empirical data and analysis which makes the collected data progressively more focused and the analysis more theoretical (Bryant \& Charmaz, 2012).

Since the main objective of this theory is to ground the concepts in the data, creativity and critical thinking on the part of researchers are elementary requirements as we are required to be open to multiple possibilities. The 
researchers need to interpret the contributions of the participants to allow the categories to emerge from the data, taking care not to impose their own pre-established categories.

Among the features of this type o research De la Torre et al. (2011) present the following:

Data collection and analysis take place concurrently.

It is the data which determine the processes and products of the research and not the preconceived theoretical frameworks.

It is the analytical processes which elicit the discovery and theoretical development and not the verification of already known theories.

Sampling is done based on what emerges from the data, it is called theoretical sampling and serves to refine, elaborate and complete the categories.

The systematic use of analytical procedures leads to more abstract levels of analysis. (p. 7)

Another fundamental characteristic of Grounded Theory is the circularity of the process. According to Glaser and Straus (1967) "although this method is a process of continuous growth - each stage after some time is transformed into the next - the previous stages remain operative throughout the analysis and provide continuous development to the next stage until the analysis is completed." In this method, there is an intertwining of the operations of data collection, coding, analysis and interpretation of information throughout the process, which reflects the holistic character of qualitative research.

\subsection{Procedure}

Based on the steps of the research method, the study followed the process below:

\subsubsection{Theoretical Sampling}

This process consists of the collection, analysis and categorization of empirical data by the researchers guided by the emerging theory. The collection and analysis are repeated until the theoretical saturation, that is, when sufficient data have already been found to develop the theory.

\subsubsection{Coding}

The general procedure in the theoretical sampling demands for the coding of the incidents, through constant comparative analysis, from the beginning of the data collection and as the data start to emerge. "Coding means categorizing segments of data with a short name that simultaneously summarizes and accounts for each piece of data. Your codes show how you select, separate and sort data to begin an analytic accounting on them" (Charmaz, 2012). Coding is the crucial link between the data colected and the development of an emergent theory. Theoretical sampling ceases when the code has been saturated, elaborated and integrated into an emerging theory.

\subsubsection{Theoretical Saturation}

During the theoretical sampling the researchers collect data and analyze them, guided by questions that arise during the process. This is how the concern arises and the researcher asks: When do we stop collecting information? It is here when the criterion of theoretical saturation is presented. The theoretical saturation can be defined as the criterion from which the researchers decide to stop sampling the different groups belonging to each of the categories. "Categories are saturated when gathering fresh data no longer sparks new theoretical insights, nor reveals new properties of these core theoretical categories" (Charmaz, 2012).

\subsubsection{Constant Comparative Method (CCM)}

The Constant Comparative Method (CCM) aims to generate theory from the comparative and systemic analysis of the incidents. This method is an element that integrates the results of the theoretical sampling and the theoretical saturation for the generation of theory. CCM is not a test of hypothesis; instead, it has as its general objective conceptual categories and properties. You use the constant comparative method to stablish analytical distinctions and make comparisons to find similarities and differences (Charmaz, 2012).

\subsection{Participants}

\subsubsection{Students From 7 and 8 Semesters of the ELT Undergraduate Program}

Seven students of the seventh and eighth semesters of the ELT Undergraduate Program were the target population of the study. There were basically two types of students, those taking the course for the first time and those repeating it. Some of those students (repeating courses) were taking the course for the second, third, fourth and even fifth time. Their ages ranged between 18-24 years and belonged mostly to medium and medium-low 
socio-economic strata. Most of them came from public schools in the city of Neiva or from municipalities in the southern region of Colombia.

The English level with which they started university was rather low and was mostly acquired in their high schools, with only a low percentage of students having taken English courses prior to the beginning of their university studies. These students had received an average of 768 hours of instruction in English from the first to the sixth semesters. During the last two semesters they had to attend four hours of English class per week for a total of 64 hours per semester. Additionally, in the last two semesters students are required to do their teaching practicum in primary and secondary and the vast majority of them start working in educational institutions mainly private ones in the city of Neiva.

\subsubsection{Professors of the ELT Undergraduate Program}

Six full time professors who had been in charge of teaching the English VII and VIII courses in the undergraduate program also played a major role in the study. Most of them hold master degrees in areas related to ELT and have between 6 and 15 years of university teaching experience. They also have an advanced level of communicative competence in English, demonstrated in international proficiency exams.

\subsection{Instruments}

The instruments used in the research study were:

\subsubsection{Initial Survey to Students}

Although this is not part of the main instruments, it was decided to administer an initial and diagnostic survey, which gave us the first data to start the theoretical sampling process. This survey was applied to all 35 students who were taking English VII and VIII at the moment the research study started during the first semester of the previous year. This was done in order to have a general idea of the perceptions not only of the students who had failed English courses but also of those who had never been in such situation. With this, we intended to have a general idea of what both types of students had to say about the course repetition problem.

\subsubsection{Initial Survey to Professors}

Likewise, an initial survey to professors teaching levels VII and VIII was administered to know their perceptions of the situation.

The data gathered through students' and professors' surveys helped us to create the questionnaire.

\subsubsection{Questionnaire}

The questionnaire (Appendix 1) is one of the main instruments of this study. It was designed and applied to the student population (7 students), who in the initial survey evidenced situations of English courses repetition and who voluntarily agreed to participate as the population of the research study by signing a consent letter. The questionnaire was administered in a virtual way through the web page www.encuestafacil.com.

The questionnaire consisted of 15 closed, dichotomous questions and one open question that asked respondents to include any additional information. A quantitative descriptive analysis using Excel was done to the data collected. The questionnaire was then validated by two research experts and later piloted by five students who were research assistants and students of the English VIII course. It yielded relevant data that was taken into account and deepened in the design of the questions for the semi-structured interview.

\subsubsection{Interview to Students and Professors}

Participant students and Professors were interviewed (Appendixes 2 and 3), with the purpose of delving into important aspects regarding the phenomenon of course repetition. Six students out of the seven who responded the questionnaire were interviewed.

The interview to students included 4 open questions; the third one provided them with seven statements to which they were asked to provide an opinion. The interview to professors consisted of 2 questions, one of them with seven statements to which they were asked to express their opinion. The questions for both students' and teachers' interviews emerged from the analysis of the questionnaire.

To ensure the validity of the questionnaire, a Likert-scale was used. It assessed the questions of the interview with a scale from 1 to 4 . Rating 1 was considered as deficient, 2 regular, 3 good and 4 excellent. The assessment criteria were clarity, objectivity and language. Two experts analyzed the questions for both interviews and it helped us to improve the questions. 
Table 1. Validity assessment grid

\begin{tabular}{|c|c|c|c|c|c|c|c|c|c|c|c|c|}
\hline \multirow[t]{2}{*}{ Questions } & \multicolumn{4}{|c|}{ Clarity } & \multicolumn{4}{|c|}{ Objetivity } & \multicolumn{4}{|c|}{ Language } \\
\hline & 1 & 2 & 3 & 4 & 1 & 2 & 3 & 4 & 1 & 2 & 3 & 4 \\
\hline 1. & & & & & & & & & & & & \\
\hline 2. & & & & & & & & & & & & \\
\hline 3. & & & & & & & & & & & & \\
\hline
\end{tabular}

\section{Results}

Following the Grounded Theory Approach, the results of the data analysis are presented following the order in which they emerged as they were gathered through the different instruments.

\subsection{Survey to Students}

Once the data obtained from this first instrument was analyzed, it was found that $40 \%$ of the participant students had failed and repeated English courses at some point along their university studies. It was also confirmed the fact that it was in the last two levels (English VII and VIII) where this situation was most evident as shown in Figure 1 below. In English VII 14.2\% of the students had failed the course while a 11.4\% had had to repeat English VIII. The percentage corresponds to a population of 35 students

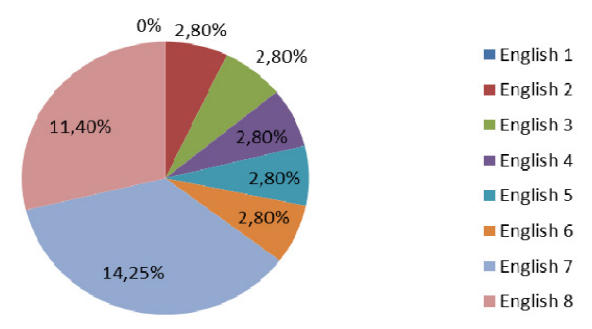

Figure 1. Academic failure rate

Additionally, in the first incidents that emerged, the factors that students attributed to academic failure were:

Lack of motivation

Lack of dedication, commitment, autonomous learning habits.

Methodology used by the teacher: dynamism / monotony

High levels of absenteeism

Work commitments and duties

Family factors

Lack of responsibility with academic duties

Reduced number of English lessons per week

\subsection{Survey to Professors}

First incidents:

According to the six professors surveyed, these are the main attributions to the problem:

Greater academic exigency in the last semesters

Lack of commitment to academic duties

Reaching the advanced courses of English with a low level of communicative competence.

Few English lessons per week

Lack of exigency in terms of evaluation, during the previous levels

Lack of independent work and autonomous learning habits 
Lack of a support program for students with difficulties

According to De la Torre, et al. (2011) "the general procedure for the theoretical sampling requires the coding of the incidents, through constant comparative analysis, from the beginning of the data collection, and as the data is appearing". Analyzing and coding the incidents obtained from these first instruments was important to begin with the generation of theory, from which a series of initial families emerged. These were later taken into account for the elaboration of questionnaires for professors and students.

\subsection{Questionnaire to Students}

According to the data obtained in the questionnaire (Figure 2) the following are the predominant reasons for course repetition during the last two semesters. They are presented in the order they were selected:

1) The high number of courses enrolled in the respective semester (reason/question \# 3)

2) The higher level of demand in the evaluation used in the last levels (\#13)

3) My communicative competence level is not the expected for advanced levels (\#14)

4) My lack of autonomous learning habits (\#15)

5) The level of demand in the evaluation used in the previous levels (\#12)

6) Work duties (\#4)

7) The reduced number of English lessons during the last semesters (\#9)

8) The low exigency of professors in the previous semesters (\#10)

9) My lack of responsibility (\#1)

10) Teachers' methodology (\#2)

11) The use of the same proficiency test in fourth and eighth levels (\#16)

12)

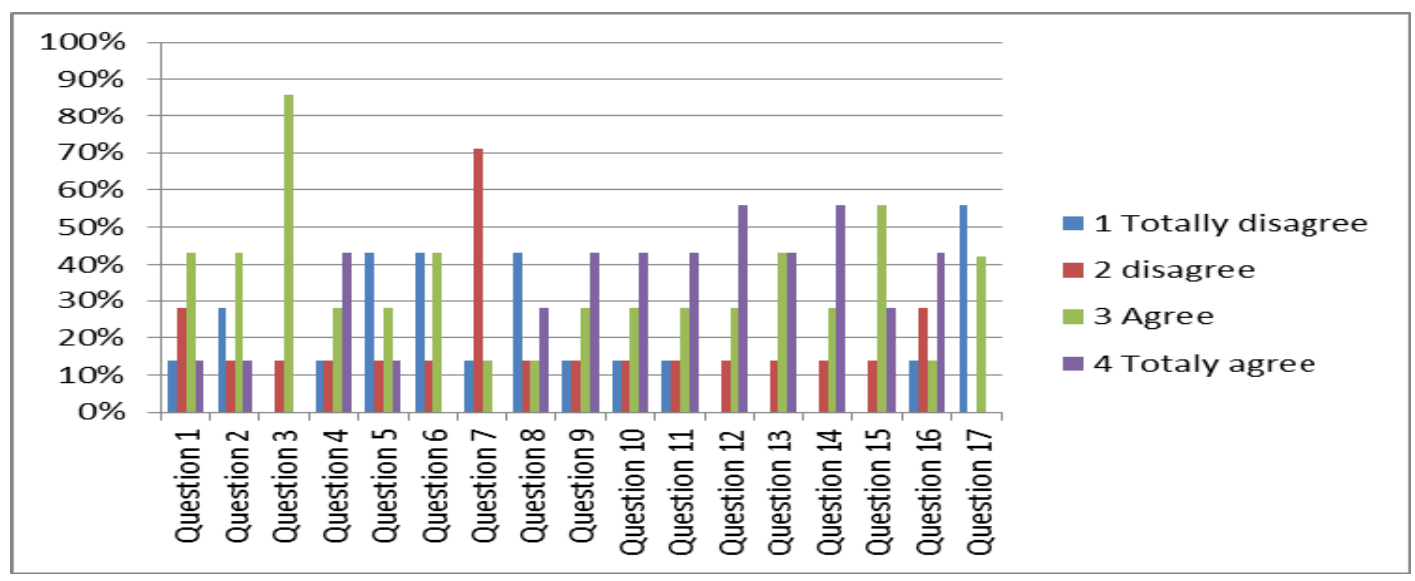

Figure 2. Questionnaire results

\subsection{Interview to Students}

Although the initial questionnaire was applied to 7 students, only 6 of them answered the interview. The analysis of the data collected via this instrument led us to confirm that in fact the categories previously identified were those that have the greatest influence on the phenomenon of English courses repetition. Although some other reasons appeared, their frequency was not enough to be considered as new categories. The following table contains those categories: 
Table 2. Emerging categories from the analysis and comparison of data collected from students

\begin{tabular}{ll}
\hline Categories & Rate \\
\hline a. There is a higher level of exigency in the evaluations used in the last 2 levels & $83.3 \%$ \\
b. My level of communicative competence in English is not the expected for advanced levels & $100 \%$ \\
$\begin{array}{l}\text { c. The lack of autonomous learning habits } \\
\text { d. The little dedication and commitment to my studies }\end{array}$ & $83.3 \%$ \\
e. Responsibilities in the workplace usually interfere with academic duties & $83.3 \%$ \\
f. The few number of English lessons per week & $83.3 \%$ \\
g. The level of exigency from the part of some teachers in the previous levels (semesters) was wo \\
lower compared to that of the teachers in the advanced levels
\end{tabular}

The analysis of the previous data helped us to conclude that the two main reasons students attributed the failure and repetition of English courses were: 1) the low level of communicative competence with which they had reached the advanced levels in the final semesters of study, and 2) the lack of exigency by some English teachers during the previous English courses. This information is important as all participants agreed in them as the main ones. As for the other reasons they confirmed what the previous questionnaire initially showed and according to the research methodology used, no new categories emerged.

\subsection{Interview to Professors}

Given the fact that our study wanted to establish the factors to which participants attributed the research problem, this instrument had the same objective and type of questions used in the student's interview (Appendix 3) which was to deepen the identification of the factors that determined the failure and repetition of English courses. In the same way, this interview sought to either identify new categories, or to reach theoretical saturation.

Like in the data gathered from the students' interviews, here we confirmed that the categories initially identified were those that have the greatest influence on the phenomenon of course repetition and there were no new emerging categories.

\subsection{Theoretical Saturation}

Once the identification and categorization of incidents was concluded, we started with the theoretical saturation. As mentioned above, it can be said that the data is saturated, when no new information emerges from the collected data.

When comparing the analysis of the final results of the interviews to teachers and students we could see that the reasons attributed by both groups to the phenomenon of English courses repetition coincided to a large extent. All participants agreed that the low level of communicative competence in English with which some students reached the advanced levels in the last two semesters was the main reason for the failure and repetition of English courses.

According to the participant-students, the second reason attributed to the phenomenon under study was the difference in the level of exigency by some English teachers. It seems that in the first semesters the exigency is lower compared to that in the last semesters. However, within the population of professors participating in the study there was disagreement with this assertion and they considered that it was the reason to which this phenomenon could least be attributed.

\subsection{Categories}

Taking into account the degree of recurrence and relevance, the following coding categories were established:

1) There is a low level of communicative competence in English that does not correspond to that expected for students in advanced levels (in the last two semesters):

Both teachers and students agreed that the low level of communicative competence in English was one of the main causes of course failure and repetition. Since this is such a complex and verifiable situation, it is important to establish in greater depth. Why does it happen? Why are some students being promoted from one semester to the next without having the level of communicative competence expected?

2) Economic factors, work and family duties affect dedication and commitment to academic duties:

Another aspect to which both teachers and students attributed the phenomenon under study was related to 
economic factors together with work and family duties. Having to attend a few classes in the seventh and eighth semesters, makes students take advantage of this extra "free" time by getting jobs sometimes in different schools at the same time. The main reason for this is that students need money to pay their expenses especially those derived from their studies. This situation is facilitated by private schools that prefer to hire students of last semesters since they represent cheap labor and reduce costs for the institutions. Additionally, there was the fact that many of those students had extra responsibilities since they were already parents and had to dedicate most of their time to meet family needs.

3) The reduced amount of English lessons in the last semesters:

The Colombian National Ministry of Education defines an Academic Credit as the unit that measures the estimated time of the student's academic activity based on the professional and academic competencies that the program is expected to develop. Additionally, the Academic Credit is equivalent to 48 contact hours, which include the time professors teach students as well as the other time used for independent study activities, practices, preparation of exams or others that are necessary to reach the proposed learning goals, not including those intended for the presentation of final exams.

Due to the implementation of the academic credits system, and some other policies issued by the National Ministry of Education to regulate higher education in the country, the ELT Undergraduate Program where the study was conducted, has made several modifications to their curriculum and as a result the number of English classes in the last semesters has been reduced. This is how in the first two semesters there are ten contact hours of English per week while in the last two there are only four hours per week.

It is evident that the low number of contact hours in English tend to affect students, especially those who have not developed good habits of independent study and therefore require constant help, supervision and guidance from their teachers.

4) The level of exigency from the part of some teachers regarding teaching methodology and evaluation criteria in the last semesters $\left(7^{\text {th }}\right.$ and $\left.8^{\text {th }}\right)$ was higher compared to that of the teachers in the first levels:

All the students agreed with the fact that there was a lower level of academic exigency in the initial levels in terms of methodology and evaluation criteria. This fact appeared as one of the main reasons for the problem under study. However, teachers did not fully share this idea. Although they recognized that the academic exigency needs to increase every semester, they also emphasize that in the initial levels there is also exigency, which in some cases generates course failure and repetition in those levels as well.

\section{5) Core Category: Lack of Autonomous Learning Habits}

Core category is the category that, due to its centrality, explains and gives meaning to all the data and its relationships and, therefore, explains the greater variability in the pattern of social behavior under study. This category allows us to see the relationships and is usually the basis of the main subject matter of investigation. The core category must be explained in terms of its importance and in relation to other base categories. (De la Torre, et al., 2011)

Once the corresponding analysis of the incidents and emerging categories was carried out, and the theoretical saturation reached, we conclude that the central category of this study was the lack of autonomous learning habits. Since this category had a close and significant relationship with most of the other main categories. By addressing it, in order to seek a solution to the research problem, the other categories will be positively affected.

The lack of autonomous learning habits is closely related to each of the coding categories previously described as can be seen in the following graph: 


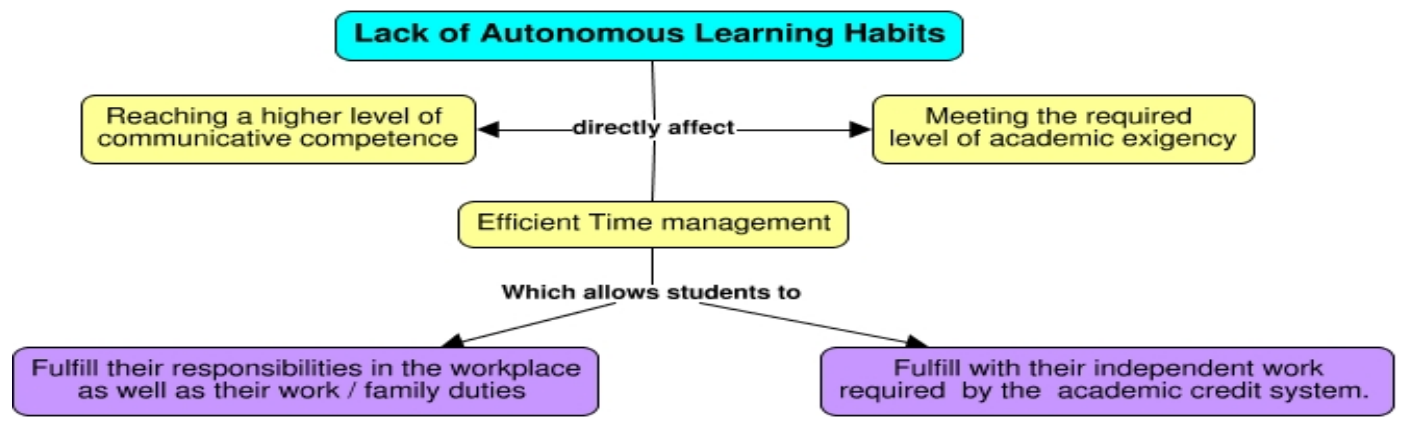

Figure 3. Core category in relation to the main coding categories

Graph 1: Core category in relation to the main coding categories.

Students who lack habits for independent work and autonomous learning can hardly reach the C1 level of communicative competence in English expected by the National Ministry of Education for ELT undergraduate programs in Colombia. In our particular context we have found cases where several students graduate with level B1, most of them achieve level B2 while a minority achieve the desired level C1. Likewise, those students who have difficulties in managing their time, whether due to family or work duties, will greatly benefit from acquiring good autonomous learning habits as this will allow them to better organize their tasks and duties so that they do not interfere with each other. In this manner, students will be able to complete their independent work required for the implementation of academic credits.

As recognized by teachers and students, the last two semesters of the program are more demanding in terms of the level of commitment and dedication required on the part of the students. The lack of autonomous learning habits only increases the problem as students are not able to fulfill with the academic expectations.

\section{Discussion}

The research question of the study is: what are the causal attributions of students and professors regarding the English course repetition phenomenon in some students from the advanced levels? To that respect and after making a sequential analysis following the grounded theory parameters, the following attributions were the most frequent:

Most of the students lack of autonomous learning habits (core category). It determines in great manner the existence of academic failure and course repetition. Both professors and students believe that it is necessary more independent work on the part of the students, which allow them to meet the demands of the course. Likewise, this fact is directly related to the other variables to which the problem is attributed. In the sense, that if the student is trained to develop effective autonomous learning habits, the other situations that are part of the problem could be addressed. "When learners succeed in developing autonomy, they not only become better language learners but they also develop into more responsible and critical members of the community in which they live" (Benson, 2001, p. 1).

All of the students of the population evidence a low level of communicative competence which does not correspond to that expected for students in the last two semesters. This is one of the main reasons for the low academic performance, that generates failure and repetition of said courses. There are often cases of students who despite losing and repeating an advanced English course, do not show significant progress due to the lacks and weaknesses with which they have been promoted semester after semester. This was also a factor evidenced by the study of Gomez (2017) who stated that among the beliefs that represented challenges for the students were some linguistic aspects and a difficulty in understanding oral messages; and these factors become a limiting factor which affect negatively their communicative competence.

On the other hand, this highlights the lack of correspondence between the teachers' and students' expectations. Although for many foreign language teachers around the world boosting students' communicative competence in the foreign language is one of the main objectives in their pedagogical practices, for many of their students, on the other hand, it is not. This agrees with what Brown (2009) identified in his study. He found that teachers apparently pay more attention to a communicative approach in which information exchanges take precedence over the practice of particular aspects of grammar. Students, by contrast, preferred an emphasis on the teaching of grammatical aspects over communicative exchanges. 
A large number of students at the end of their studies acquire financial, work and family duties, which often interfere in their academic performance, since they spend most of their time working to carry out their responsibilities and leave their studies aside. Most of the population who evidenced academic failure during the last semesters were already working and evidenced time-management difficulties. This concurs with Roman's study (2014), who found that economic and financial causes are basic for students failure at tertiary level.

Another factor that was identified within the perceptions of the participating population as a determinant of the problem under study is the reduced amount of English lessons in the last semesters of the program. This fact seriously affects those students who lack autonomous learning habits and who depend exclusively on class attendance and teachers' explanations; since less hours of class requires more dedication and independent work.

Finally, another reason to which the problem is attributed is the difference in the level of exigency in terms of methodology and evaluation criteria between teachers of the first and last levels of English. Some students tend to blame their teachers for their failures during their foreign language learning process and allege inadequate methods; specifically, in this study, they claim to have over demanding teachers during the last semesters, and a lack of correspondence in the methodology of professors of first semesters and last semesters It was also identified by Williams et al. (2001), in their study, students attributed their academic failure to, among other factors, inadequate methods and lack of support from family and teachers

Nevertheless, participants coincide when accepting that this is a logical phenomenon since the higher the level the higher the rigorousness and demand. It should be noted that many students do not respond with what is required for these levels because they do not have independent or autonomous learning habits, nor the expected level of communicative competence, additionally they struggle with their time management.

Finally, taking into account what Kalaja \& Barcelos (2003) state, attributions do not necessarily reflect the "true" reasons why an individual can succeed or fail in any task. Rather, attributions are the perceived explanations that the individual constructs about their good or bad performance in any area; which makes the attributional theory more powerful than the real reasons. The attributions given by this group of teachers and students are fundamental for the analysis and understanding of the constant course repetition phenomenon. Likewise, besides the reasons stated in categories can be considered as true, since they were mentioned by the majority of the population, which means they were socially constructed because it was a shared discourse about why they feel are not able to achieve the level expected.

\section{Recommendations}

Below, we present some alternatives to face the phenomenon of repetition of courses associated with low academic performance:

Increase in the number of English courses and elective courses related to the English area and academic credits, in such a way that students are exposed for more time to the significant use of the language.

Standardization of evaluation criteria among the teachers of the different English courses of the program. This can be carried out during the meetings with the area coordination at the beginning of the semester, to ensure that from the first semesters of the program teachers work in a unified manner, also guaranteeing a high level of demand from the beginning to the end of studies.

Implementation of strategies to promote the constant use of English by teachers and students both inside and outside the classroom.

Design and implementation of strategies and action plans for the early detection of cases of students vulnerable to academic failure from the first semesters. This can be carried out through academic counseling and the use of some instruments specifically designed for that purpose.

Creation of an action plan for the students of last semesters that show cases of failure and repetition of English courses.

Preparation of a research proposal towards the creation and implementation of an action plan to promote the development of autonomous learning habits in the students of the Foreign Language English program.

\section{References}

Barrios, E. (2014). Creencias sobre el aprendizaje de una lengua del futiro profesorado de inglés de educación primaria. PortaLinguarum, 22, 73-93.

Benson, P. (2001). Teaching and Researching Autonomy in Language Learning. Edinburgh: Pearson Education.

Bisquerra, R. (2014). Metodología de la Investigación Educativa. Madris: La Muralla. 
Breen, M. P. (2014). Learner Contributions to Language Learning: New Directions in Research. New York: Routledge.

Brown, A. (2009). Students' and Teachers' Perceptions of Effective Foreign Language Teaching. The Modern Language Journal, 93(1), 46-60. https://doi.org/10.1111/j.1540-4781.2009.00827.x

Bryant, A., \& Charmaz, K. (2012). The Sage Handbook of Grounded Theory. London: SAGE.

Cortez, K., Fuentes, V., Villablanca, I., \& Guzmán, C. (2013). Creencias docentes de profesores ejemplares y su incidencia en las prácticas pedagógicas. Estudios Pedagógicos, XXXIX(2), 97-113. https://doi.org/10.4067/S0718-07052013000200007

Charmaz, K. (2012). Constructing Grounded Theory. Los Angeles: SAGE.

Creswel, J. (2014). A concise Introduction to Mixed Methods Research. Thousand Oaks, Ca: SAGE.

Creswell, J. (2015). A Concise Introduction to MIxed Methods research. Thousand Oaks: SAGE.

De la Torre, G., E, D. C., Florido, A., Opazo, H., Ramírez, C., Rodríguez, P., ... Tirado, J. (2011). Teoría Fundamentada o Grounded Theory. Universidad Autónoma de Madrid (Links). Recuperado el Julio de 2017,

https://s3.amazonaws.com/academia.edu.documents/8257892/teoria-fundamentada_\%28trabajo\%29.pdf?A WSAccessKeyId=AKIAIWOWYYGZ2Y53UL3A\&Expires $=1520095030 \&$ Signature $=1 \mathrm{G} \% 2 \mathrm{FJwdu} 8 \mathrm{iVEzZ}$ $35 \mathrm{qEPmIsbGB} \% 2 \mathrm{~F} 7 \mathrm{o} \% 3 \mathrm{D} \&$ response-content-disposition $=$ inline $\% 3 \mathrm{~B} \% 20$ filename\%3DTeoria_Fu

Fernández, A., Arnaiz, P., Mejía, R., \& Barca, A. (2015). Atribuciones causales del alumnado universitario de República Dominicana con alto y bajo rendimiento académico. Revista de estudios e investigación e psicología y educación, 92, 19-29. https://doi.org/10.17979/reipe.2015.2.1.1319

Glaser, B., \& Straus, A. (1967). The Discovery of Grounded Theory: Strategies for qualitative research. New York: Aldine Publishing.

González, L. E. (2005). Repitencia y Deserción Universitaria en America Latina. Seminario sobre el Rezago y la Deserción Universitaria en America Latina y el Caribe (pp. 156-168. Cap 11). Talca, Chile.

Gómez, J. F. (2017). Creencias sobre el aprendizaje de una lengua extranjera en el contexto universitario. Íkala, Revista de Lenguaje Y Cultura, 22(2), 203-219. https://doi.org/10.17533/udea.ikala.v22n02a03

Hawkey, R. (2006). Teachers and Learners Perceptions of Language Learning Activity (Vol. 60). Oxford: Oxford University Press.

Holmes, C., \& Matthews, K. (1984). The Effects of Nonpromotion on the Elementary and Junior high School Pupils: A Meta-analysis. Review of Educational Research, 54, 225-236. https://doi.org/10.3102/00346543054002225

Jackson, L. (1975). The Research Evidence on the Effect of Grade Retention. Review of Educational Research, 45(4), 613-635. https://doi.org/10.3102/00346543045004613

Kalaja, P., \& Barcelos, M. (2003). Beliefs about SLA: New research approaches. Amsterdam: Kluver Academic. https://doi.org/10.1007/978-1-4020-4751-0

Larenas, C., \& Campos, H. (2015). Creencias de estudiantes de primaria sobre el aprendizaje del inglés, en un establecimiento educacional chileno. Actualidades Investigativas en Educación, 15(1), 1-20.

Mercer, S. (2008). Learner Self- beliefs. Key Concepts in ELT, 182-183.

Pajares, M. F. (1992). Teachers' Beliefs and Educational Research: Cleaning Up a Messy Construct. Review of Educational Research, 62(3), 307-332. https://doi.org/10.3102/00346543062003307

Richardson, V. (1996). The role of attitudes and beliefs in learning to teach. En J. Sikula, Handbook of research on teacher education (2nd ed., pp. 102-119). New York: Mcmillan.

Roman, M. (2014). Students Failure in Academic Environment. Procedia- Social and Behavioral Sciences, 114, 170-177. https://doi.org/10.1016/j.sbspro.2013.12.679

Shepard, L. (1989). Flunking grades: Research and Policies on retention. Philadelphia: Falmer Press.

Weiner, B. (1985). An attributional theory of achievement, motivation and emotion. Psychological Review, 548-573. https://doi.org/10.1037/0033-295X.92.4.548

Williams, B., Burden, R., \& Al-Baharna, S. (2001). Making sense of sucess and failure: The role of the individual in motivation theory. In Z. Dörnyei, \& R. Schmidt (Eds.), Motivation and second language 
acquisition. Technical report (Vol. 23, pp. 171-184). Honolulu: University of Hawai'i, Second Language Teaching and Curriculum Center.

Williams, M., Burden, R., Poulet, G., \& Maun, I. (2004). Learners' perceptions of their successes and failures in foeign language learning. Language Learning Journal, 30(1), 19-2. https://doi.org/10.1080/09571730485200191

\section{Appendix A}

\section{Students questionnaire}

Objective: Identify decisive factors in the English Courses repetition phenomenon at the ELT Undergraduate Program

Answer the following questionnaire by checking the option that best indicates how well you agree with the influence of the following factors on your repetition of English courses.

Consider the following parameters:

1: Totally disagree. $\quad 2$ : Disagree
3: Agree.
4: Totally agree.

The determining factors of my English level(s) repetition throughout my studies have been:

1. My lack of responsibility

$1 \_2 \_3 \_4 \_5$

2. Teachers' methodology
$1 \_2$
3
4

5

3. The high number of courses enrolled in the respective semester

$1 \_2 \_3 \_4 \_5$

4. Work duties

$1 \_2 \_3 \_4 \_5$

5. My lack of motivation

$1 \_2 \_3 \_4 \_5$

6. My lack of interest

$1 \_2 \_3 \_4 \_5$

7. The little dedication and commitment with my studies

$1 \_2 \_3 \_4 \_5$

8. The constant absence from classes

$1 \_2 \_3 \_4 \_5$

9. The reduced number of English lessons during the last semesters

$1 \_2 \_3 \_4 \_5$

10. The low exigence of professors in the previous semesters

$1 \_2 \_3 \_4 \_5$

11. The higher exigence of professors in the last semesters

$1 \_2 \_3 \_4 \_5$

12. The level of demand in the evaluation used in the previous levels

$1 \_2 \_3 \_4 \_5$

13. The higher level of demand in the evaluation used in the last levels

$1 \_2 \_3 \_4 \_5$

14. My communicative competence level is not the expected for advanced levels

$1 \_2 \_3 \_4 \_5$ 
15. My lack of autonomous learning habits

$1 \_2 \_3 \_4 \_5$

16. The use of the same proficiency test in fourth and eighth levels

$1{ }^{2}{ }^{3}{ }^{3} \_4$

17. Other reasons /family issues

$1 \_2 \_3 \_4 \_5$

Apart from the above aspects, do you think there are others that are decisive for the constant loss and repetition of English courses?

YES NO

Which are them? :

\section{Appendix B}

\section{Questions for the interview to students}

Objective: Identify decisive factors in the English Courses repetition phenomenon at the ELT Undergraduate Program

1. First of all we would like to know how many times you have repeated one or both of the last levels of English (7 and 8) of the program

2. In your particular case, what are the reasons for the repetition of these courses?

3. According to the results of the questionnaire applied to students in previous months, the following are the factors that most influence the repetition of English courses in the last semesters; we would like to know what you think about each of them and how these factors have affected you, if that is the case:

a. There is a higher level of demand in the evaluation used in the last 2 levels of English compared to that used in previous semesters.

b. My level of communicative competence in English is not what is expected for advanced levels.

c. the lack of autonomous learning habits.

d. the little dedication and commitment to my studies.

e. Work duties that interfere with academic commitments.

f. Reduced amount of English lessons in the last semesters.

g. The low exigence of professors in the previous semesters, compared to the professors' level of demand in the last semesters.

4. Apart from the previous reasons, do you think there is another that has influenced your particular case? Which one(s)?

\section{Appendix C}

\section{Questions for the Interview to Professors}

Objective: Identify decisive factors in the English Courses repetition phenomenon at the ELT Undergraduate Program

1. According to the results gathered from the questionnaire administered to students of the last semesters, the following are the factors which most influence the English course repetition phenomenon in said levels. We would like to know what you think about each of them and how these factors affect students' academic performance.

a. Some students' level of communicative competence in English is not what is expected for advanced levels.

b. The lack of autonomous learning habits.

c. The students' little dedication and commitment to their studies. 
d. Work duties that interfere with academic commitments.

e. Reduced amount of English lessons in the last semesters.

f. The low exigence of professors' methodology and evaluation techniques in the previous semesters, compared to the professors' level of demand in the last semesters.

2. Apart from the previous factors, do you think there is another that has influenced your particular case? Which one(s)?

\section{Copyrights}

Copyright for this article is retained by the author(s), with first publication rights granted to the journal.

This is an open-access article distributed under the terms and conditions of the Creative Commons Attribution license (http://creativecommons.org/licenses/by/4.0/). 